\title{
Does a "moderate" alcohol intake damage the brain?
}

\author{
CLIVE HARPER, ${ }^{*} \dagger$ JILLIAN KRIL, * JOHN DALY $\ddagger$ \\ From the Department of Pathology, ${ }^{*}$ The University of Sydney, Sydney, NSW, Department of Anatomical \\ Pathology, Royal Prince Alfred Hospital, $\uparrow$ NSW, Department of Neuropathology, Royal Perth Hospital, $\ddagger$ \\ Perth, WA, Australia
}

\begin{abstract}
SUMMARY A range of volumetric and neurochemical analyses were carried out on the brains of 14 "moderate" drinkers. These data were compared with previous studies from controls and alcoholics. Volumetric measurements consistently suggest a loss of cerebral tissue although the differences were not statistically significant. Changes in the lipid and water content of the white matter were noted and the significance of these changes in relation to the pathogenesis of reversible brain shrinkage caused by alcohol abuse is discussed.
\end{abstract}

There is a considerable volume of clinical, ${ }^{12}$ neuroradiological, ${ }^{34}$ neuropsychological ${ }^{5}$ and neuropathological ${ }^{6-9}$ data concerning the long term effects of alcohol abuse on the human central nervous system. A large proportion of these data, particularly with regard to neuropathological changes, deals with severe chronic alcoholism. The interpretation of such data is difficult because of the frequency of occurrence of attendant disorders such as cirrhosis of the liver and nutritional deficiency disorders (Wernicke's encephalopathy) in the more advanced cases of alcoholism. Of particular interest to the general public is the long term effects of a moderate alcohol intake which many would equate with "social" drinking.

\section{Materials and methods}

Cases for the studies cited in this paper were selected from the Perth City Coroner's Department and the Royal Perth and Royal Prince Alfred Hospitals., The authors classified the cases according to the following criteria:

1 Controls: teetotal or less than 20 grams of ethanol per day.

2 Moderate: $30-80$ grams per day.

3 Alcoholic: greater than 80 grams per day but without additional medical problems such as cirrhosis or Wernicke's encephalopathy (WE).

4 Alcoholic and cirrhosis: as for (3) plus pathologically confirmed alcoholic cirrhosis (without WE).

5 Alcoholic and WE: as for (3) plus pathologically confirmed Wernicke's encephalopathy (without cirrhosis).

(Approximately $10 \mathrm{~g}$ of ethanol is contained in one public

Address for reprint requests: Professor C G Harper, Department of Pathology, The University of Sydney, Sydney, NSW 2006, Australia.

Received 17 November 1987 and in revised form 18 February 1988. Accepted 7 March 1988 house serve of alcohol that is, half a pint $(284 \mathrm{ml})$ of beer, $4 \mathrm{fl} \mathrm{oz}(110 \mathrm{ml})$ wine, $1 \mathrm{fl} \mathrm{oz}(28 \mathrm{ml})$ spirits. $\left.{ }^{10}\right)$

Categorisation of individual cases was based on a compilation of clinical and pathological data. These data included clinical notes from the teaching hospitals as a result of previous admissions, detailed questionnaires on the alcohol intake provided by the relatives of the subjects and a complete necropsy with microscopic examination of tissues including the liver and brain. Our definition of the moderate drinking group (20-80 g of alcohol/day) is not meant to correlate with oft quoted clinical definitions of moderate or social drinking. In the most recent literature figures vary from 30 to 70 grams per day. ${ }^{1112}$ In the recent report on "Is there a safe level of daily consumption of alcohol for men and women?" from the Australian National Health and Medical Research Council, the authors recommend that a safe daily intake is $\mathbf{4 0}$ grams for men and 20 grams for women. ${ }^{13}$ From a pathological point of view it is an extremely difficult group to categorise on the basis of the retrospective collection of data on drinking habits. Thus it was necessary to utilise a wider range of alcohol intake $(30-80 \mathrm{~g} /$ day $)$ than is generally quoted in clinical papers. Patients with a history or pathological evidence of a neurological disease, other than those associated with alcoholism, were excluded as were any patients with evidence of head injury. All the cases in these studies were male. Data on female cases have been collected but there is an inadequate number of cases for statistical analyses. Separation of data on a sex basis is important as there is evidence from human studies and animal models of alcohol toxicity that males and females may be affected differently. ${ }^{2} 14$

The procedures and techniques utilised in determining the various parameters have been described in previous papers relating to changes in the alcoholic groups.915-20 Samples from the frontal, parietal and occipital white matter of the right hemisphere were used for the various neurochemical assays. The water content was determined by weighing the tissue before and after drying to a constant weight. ${ }^{21}$ The dried residue was acid digested and the sodium and potassium concentration determined by flame photometry. ${ }^{22}$ The 
lipids were extracted into a chloroform/methanol mixture and aliquots used for each analysis. The total lipid was determined by drying ${ }^{23}$ and the phospholipid and cholesterol by commercial assay packages. ${ }^{24}$ The specific gravity was measured on a kerosene/bromobenzene gradient column. ${ }^{24}$ The water soluble protein was determined by the Biuret method. ${ }^{26}$ The methods are all standard laboratory procedures and each is accurate and reproducible. ${ }^{21-25}$

The left hemisphere was fixed and then sectioned at $3 \mathrm{~mm}$ intervals in the coronal plane and morphometric quantitation of the volume of the cerebral cortex, white matter and diencephalic structures ("basal ganglia") performed. An error of less than $2 \%$ is involved in the determination of these volumes. ${ }^{26}$ The pericerebral space (PICS) was determined by measuring the intracranial cavity volume with a polyurethane cast. ${ }^{16}$ The error in this technique is less than $2 \%{ }^{16}$

Although there is a considerable amount of additional information included in the tabular data the principal aim of this paper is to address the issue of the pathological changes in the brains of men regularly drinking between 30 and 80 grams of alcohol per day. The control and alcohol data are used for comparison.

\section{Results}

Two hundred and forty cases have been studied to date but it was necessary to exclude many of these because the clinical and pathological information did not enable us to be confident in classifying the cases into one of the five groups as outlined in Materials and Methods.

Table 1 summarises the numbers of cases, the mean

Table 1 Mean age, body weight and height for each of the control, moderate and alcoholic groups

\begin{tabular}{|c|c|c|c|c|c|c|c|}
\hline & \multirow{2}{*}{$n$} & \multicolumn{2}{|c|}{$\begin{array}{l}\text { Mean age } \\
\text { (years) }\end{array}$} & \multicolumn{2}{|c|}{$\begin{array}{l}\text { Body height } \\
(\mathrm{cm})\end{array}$} & \multicolumn{2}{|c|}{$\begin{array}{l}\text { Body weight } \\
(\mathrm{kg})\end{array}$} \\
\hline & & mean & $(S D)$ & mean & $(S D)$ & mean & $(S D)$ \\
\hline \multirow{6}{*}{$\begin{array}{l}\text { Control } \\
\text { Moderate } \\
\text { Alcoholic } \\
\text { Alcoholic + } \\
\text { cirrhosis } \\
\text { Alcoholic + } \\
\text { WE }\end{array}$} & 41 & 53 & (20) & 172 & (6) & 70 & (13) \\
\hline & 14 & 53 & (16) & 173 & (11) & 73 & (17) \\
\hline & 28 & 55 & (14) & 171 & (9) & 70 & (17) \\
\hline & 14 & 58 & (8) & 173 & (8) & 69 & (8) \\
\hline & & & & & & & \\
\hline & 13 & $62^{*}$ & (10) & 170 & (7) & 65 & (12) \\
\hline
\end{tabular}

$*=\mathrm{p}<0.05$.
Table 3 Cerebral grey matter, white matter and basal ganglia volume as a percentage of the cerebral hemisphere volume

\begin{tabular}{|c|c|c|c|c|c|c|}
\hline & \multicolumn{2}{|c|}{$\begin{array}{l}\text { Cortex } \\
(\%)\end{array}$} & \multicolumn{2}{|c|}{$\begin{array}{l}\text { White matter } \\
(\%)\end{array}$} & \multicolumn{2}{|c|}{$\begin{array}{l}\text { Basal ganglia* } \\
(\%)\end{array}$} \\
\hline & mean & $\overline{(S D)}$ & mean & $\overline{(S D)}$ & $\overline{\text { mean }}$ & $(S D)$ \\
\hline $\begin{array}{l}\text { Control } \\
\text { Moderate } \\
\text { Alcoholic } \\
\text { Alcoholic + }\end{array}$ & $\begin{array}{l}54 \cdot 6 \\
55 \cdot 3 \\
54 \cdot 7\end{array}$ & $\begin{array}{l}(2.6) \\
(2.9) \\
(2.6)\end{array}$ & $\begin{array}{l}40.4 \\
39 \cdot 6 \\
39 \cdot 7\end{array}$ & $\begin{array}{l}(2 \cdot 8) \\
(2 \cdot 8) \\
(2 \cdot 4)\end{array}$ & $\begin{array}{l}5 \cdot 0 \\
5 \cdot 1 \\
5 \cdot 0\end{array}$ & $\begin{array}{l}(0.4) \\
(0.4) \\
(0.4)\end{array}$ \\
\hline $\begin{array}{l}\text { cirrhosis } \\
\text { Alcoholic + WE }\end{array}$ & $\begin{array}{l}55 \cdot 4 \\
57 \cdot 5 t\end{array}$ & $\begin{array}{l}(3 \cdot 8) \\
(3 \cdot 0)\end{array}$ & $\begin{array}{l}38 \cdot 6 \\
37 \cdot 2 \dagger\end{array}$ & $\begin{array}{l}(4 \cdot 4) \\
(2 \cdot 8)\end{array}$ & $\begin{array}{l}5 \cdot 0 \\
5 \cdot 0\end{array}$ & $\begin{array}{l}(0 \cdot 4) \\
(0 \cdot 7)\end{array}$ \\
\hline
\end{tabular}

age and mean body height and weight in each of the groups. The mean body height and weight for each group are not statistically different. Undernutrition is therefore not responsible for the changes found. Loss of brain tissue or brain shrinkage is reflected in a variety of measurable parameters. These include fresh brain weight, cerebellar weight, ventricular volume and a measurement of the difference between the brain volume and the intracranial volume; this latter volume has been called the pericerebral space (PICS) and is the most accurate indicator of brain shrinkage or swelling for an individual case. ${ }^{16}$ The mean values of each parameter for each of the five groups are listed in table 2. Although there is no statistical difference between the moderate and control groups there is a trend suggesting loss of cerebral hemisphere tissue with a reduced brain weight, increased ventricular volume and increased PICS value. The mean cerebellar weight was the same in control and moderate groups. It was only significantly reduced in the WE group.

In order to localise the tissue loss to specific regions of the brain, morphometric quantitation of the volumes of cerebral cortex, white matter and basal ganglia were carried out. These are shown in table 3. As might be anticipated there is no significant loss of tissue from any of the regions in the moderate group but the trend appears to follow the alcoholic groups

Table 2 Brain and cerebellar weight, ventricular volume and pericerebral space for each of the Groups

\begin{tabular}{|c|c|c|c|c|c|c|c|c|}
\hline & \multicolumn{2}{|c|}{ Fresh brain weight $(g)$} & \multicolumn{2}{|c|}{ Cerebellar weight (g) } & \multicolumn{2}{|c|}{ Ventricular volume (\%) } & \multicolumn{2}{|c|}{$\operatorname{PICS}^{*}(\%)$} \\
\hline & mean & $(S D)$ & mean & $(S D)$ & mean & $(S D)$ & mean & $(S D)$ \\
\hline $\begin{array}{l}\text { Control } \\
\text { Moderate } \\
\text { Alcoholic } \\
\text { Alcoholic + cirrhosis } \\
\text { Alcoholic + WE }\end{array}$ & $\begin{array}{l}1438 \\
1415 \\
1352 \ddagger \\
1377 \\
13108\end{array}$ & $\begin{array}{l}(102) \\
(129) \\
(144) \\
(140) \\
(147)\end{array}$ & $\begin{array}{l}186 \\
187 \\
177 \\
176 \\
165 \ddagger\end{array}$ & $\begin{array}{l}(15) \\
(20) \\
(13) \\
(15) \\
(12)\end{array}$ & $\begin{array}{l}1 \cdot 29 \\
1 \cdot 65 \\
2 \cdot 40 \ddagger \\
2 \cdot 96 \ddagger \\
2 \cdot 34 \ddagger\end{array}$ & $\begin{array}{l}(0 \cdot 7) \\
(0 \cdot 8) \\
(1 \cdot 3) \\
(0 \cdot 8) \\
(0 \cdot 6)\end{array}$ & $\begin{array}{c}7 \cdot 3 \\
9 \cdot 8 \\
11 \cdot 0 \ddagger \\
13 \cdot 6 \$ \\
15 \cdot 9 \S\end{array}$ & $\begin{array}{l}(3 \cdot 9) \\
(4 \cdot 4) \\
(5 \cdot 8) \\
(2 \cdot 9) \\
(5 \cdot 8)\end{array}$ \\
\hline
\end{tabular}

*PICS = Pericerebral space as percentage of intracranial space.

$t=p<0.05$

$t=\mathrm{p}<0.01$.

$\S=\mathrm{p}<0.001$. 
Does a "moderate" alcohol intake damage the brain?

Table 4 Mean percentage water, total lipid, cholesterol and phospholipid content for each group

\begin{tabular}{|c|c|c|c|c|c|c|c|c|}
\hline & \multicolumn{2}{|c|}{ Water content (\%) } & \multicolumn{2}{|c|}{ Total lipid (\% DW) } & \multicolumn{2}{|c|}{ Cholesterol ( $\mu \mathrm{mol} / \mathrm{g} \mathrm{DW})$} & \multicolumn{2}{|c|}{ Phospholipid ( $\mu \mathrm{mol} / \mathrm{g} \mathrm{DW}$ ) } \\
\hline & mean & $(S D)$ & mean & $(S D)$ & mean & $(S D)$ & mean & $(S D)$ \\
\hline $\begin{array}{l}\text { Control } \\
\text { Moderate } \\
\text { Alcoholic } \\
\text { Alcoholic + cirrhosis } \\
\text { Alcoholic + WE }\end{array}$ & $\begin{array}{l}70 \cdot 4 \\
69 \cdot 6 \\
70 \cdot 6 \\
71 \cdot 4 \\
72 \cdot 1\end{array}$ & $\begin{array}{l}(1.4) \\
(1.7) \\
(1.4) \\
(1.9) \\
(3.0)\end{array}$ & $\begin{array}{l}18 \cdot 3 \\
19 \cdot 2^{*} \\
18 \cdot 3 \\
18 \cdot 2 \\
17 \cdot 3\end{array}$ & $\begin{array}{l}(1.3) \\
(1.4) \\
(1.9) \\
(1 \cdot 1) \\
(2.0)\end{array}$ & $\begin{array}{r}100 \cdot 8 \\
102 \cdot 0 \\
101 \cdot 1 \\
94 \cdot 8 \\
90 \cdot 5\end{array}$ & $\begin{array}{l}(11.6) \\
(10.9) \\
(14.9) \\
(8.6) \\
(8.4)\end{array}$ & $\begin{array}{l}25 \cdot 7 \\
26 \cdot 8 \\
25 \cdot 1 \\
23 \cdot 7 \\
24 \cdot 6\end{array}$ & $\begin{array}{l}(2 \cdot 8) \\
(1 \cdot 1) \\
(2 \cdot 5) \\
(2 \cdot 1) \\
(2 \cdot 1)\end{array}$ \\
\hline
\end{tabular}

DW $=$ dry weight.

$*=\mathrm{p}<0.05$.

Table 5 Specific gravity, electrolyte concentration and water soluble protein content of the white matter for each group

\begin{tabular}{|c|c|c|c|c|c|c|c|c|}
\hline & \multirow{2}{*}{\multicolumn{2}{|c|}{ Specific gravity }} & \multirow{2}{*}{\multicolumn{2}{|c|}{$\frac{\text { Sodium }}{\text { (mEq/l00gdry weight) }}$}} & \multicolumn{2}{|c|}{ Potassium } & \multirow{2}{*}{\multicolumn{2}{|c|}{ Protein (mg/g WW) }} \\
\hline & & & & & & & & \\
\hline & $\overline{\text { mean }}$ & $(S D)$ & mean & $(S D)$ & mean & $(S D)$ & mean & $(S D)$ \\
\hline $\begin{array}{l}\text { Control } \\
\text { Moderate } \\
\text { Alcoholic } \\
\text { Alcoholic + cirrhosis } \\
\text { Alcoholic + WE }\end{array}$ & $\begin{array}{l}1.0404 \\
1.0406 \\
1.0411 \\
1.0386^{*} \\
1.0384^{*}\end{array}$ & $\begin{array}{l}(0.002) \\
(0.003) \\
(0.002) \\
(0.002) \\
(0.002)\end{array}$ & $\begin{array}{l}17 \cdot 6 \\
15 \cdot 7 \\
17 \cdot 3 \\
18 \cdot 5 \\
17 \cdot 7\end{array}$ & $\begin{array}{l}(2 \cdot 7) \\
(2 \cdot 3) \\
(3 \cdot 0) \\
(3 \cdot 2) \\
(0 \cdot 7)\end{array}$ & $\begin{array}{l}20 \cdot 8 \\
19 \cdot 7^{*} \\
19 \cdot 7^{*} \\
17 \cdot 7^{\ddagger} \\
18 \cdot 9^{*}\end{array}$ & $\begin{array}{l}(1 \cdot 5) \\
(1 \cdot 5) \\
(1 \cdot 5) \\
(1 \cdot 7) \\
(2 \cdot 7)\end{array}$ & $\begin{array}{l}22 \cdot 8 \\
22 \cdot 8 \\
23 \cdot 2 \\
19 \cdot 8 \dagger \\
22 \cdot 7\end{array}$ & $\begin{array}{l}(2 \cdot 3) \\
(2 \cdot 8) \\
(2 \cdot 4) \\
(2 \cdot 4) \\
(1 \cdot 8)\end{array}$ \\
\hline
\end{tabular}

$\mathbf{W W}=$ wet weight.

$* \mathrm{p}<0.05$.

$t=\mathrm{p}<0.01$

$\ddagger=\mathrm{p}<0.001$

in which it has been previously shown that the loss of tissue is largely from the white matter. ${ }^{7}$

To pursue the finding of a reduction in the volume of the white matter, blocks were taken from the fresh hemisphere for neurochemical evaluation. Water, lipid and protein content, specific gravity and electrolyte concentration were determined in each case. The mean results for each group of cases are shown in tables 4 and 5 . Changes are relatively small in the moderate group but the point of interest is that the water and lipid profiles appear to move in the opposite direction to those of the alcoholic groups (table 6). The figure demonstrates, graphically, the changes in water and lipid content with increasing alcohol intake. The significance values for these results are listed in table 4 . It should be noted that we have studied only a relatively small number of "moderate" cases and these preliminary results must be followed up by a larger study in order to confirm or refute these findings.

Table 6 Patterns of change in the water and lipid content of the cerebral white matter

\begin{tabular}{|c|c|c|c|}
\hline & $\begin{array}{l}\text { Water } \\
\text { content }\end{array}$ & Phospholipid & Cholesterol \\
\hline $\begin{array}{l}\text { Normal maturation } \\
\text { Ageing } \\
\text { Moderate drinkers } \\
\text { Alcoholics } \\
\text { Alcohol toxicity models } \\
\text { Wallerian degeneration } \\
\text { Multiple sclerosis }\end{array}$ & & & \\
\hline
\end{tabular}

NA $=$ data not available.
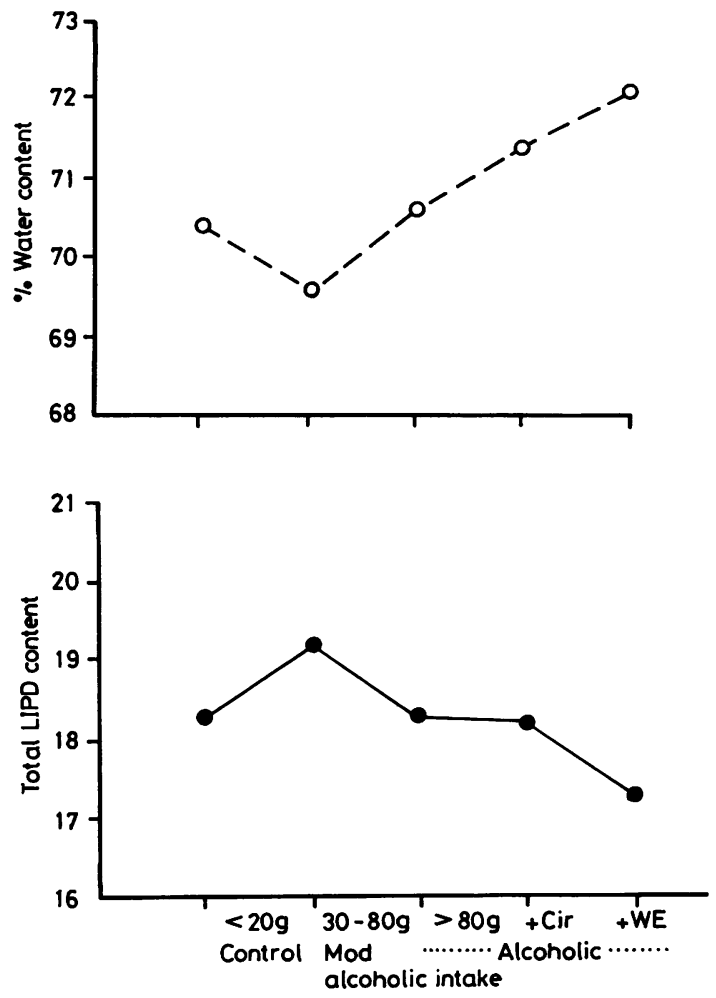

Fig Changes in lipid and water content of the white matter with increasing intake of alcohol. 
The electrolyte concentration (sodium and potassium) of the white matter, the specific gravity and water soluble protein content were also determined in all cases. The mean results are shown in table 5. The potassium value in the moderate group is significantly different from the control group. The reduction in potassium concentration is similar to that seen in the alcoholic groups. The protein content and specific gravity are unchanged from those of the control group.

\section{Discussion}

Brain shrinkage, reduced white matter volume, loss of neurons in the frontal lobes and cerebellar vermis have been previously documented in the alcoholic groups. ${ }^{7920}$ The interest in this study was to try to identify changes in the brains of a group of cases who could be defined as moderate or perhaps even "social" drinkers. A previous CT study of "social" drinkers has shown a high proportion to have significant brain shrinkage. ${ }^{4}$ The results of these studies could be said to be inconclusive because most of the changes are not statistically significant. However, there is a consistent trend in that all volumes and weights suggest a loss of cerebral tissue. Moreover in the context of the brain shrinkage measurements which are already well documented in alcoholics ${ }^{720}$ and the fact that there appears to be a pattern of severity of changes within the alcoholic groups (those with cirrhosis or WE) (see table 2), it is interesting to note that the moderate drinkers seem to fit between the controls and the medically uncomplicated alcoholic group. However the neurochemical studies show a different trend. The water content rises and the lipid content falls in the alcoholic groups whereas the water content appears to fall and the lipid content rises in the moderate group (see figure and table 6). How could this be explained on anatomical or pathological grounds? It is obvious that for a given sample of brain tissue the lipid and water content should move in concert. White matter is composed of approximately $70 \%$ water, $20 \%$ lipids and $10 \%$ protein. ${ }^{27}$ As most of the lipid and protein is combined to form membranes (myelin in particular), if there is an increase in lipid content there will be a decrease in water content and vice versa. Neurochemical studies of the white matter from demyelinating lesions show an increase in water content and a decrease in lipid content. ${ }^{28} \mathrm{How}$ ever, the magnitude of the changes is much greater than in the moderate drinkers. A similar pattern is seen in Wallerian degeneration ${ }^{29}$ although most of these studies have utilised experimental models. During maturation of the brain with active myelination the patterns are reversed: a decrease in the water content and an increase in the lipid con- tent. ${ }^{27}$ The lipid and water changes noted in the moderate and uncomplicated alcoholic groups may, therefore, be an indication of some subtle structural change in the white matter.

Few other studies of the effects of chronic alcohol abuse on the structural lipids in the human brain have been carried out. Lesch and his colleagues ${ }^{30}$ studied eight cases with hepatocerebral degeneration; six of these cases were alcoholics. They showed a significant loss of phospholipids and cholesterol in the myelin rich areas of the brain. In relatively acute alcohol toxicity animal models it has been shown that the content of one of the membrane lipids, cholesterol, is increased. ${ }^{31}$

Many clinical ${ }^{1}$ and neuroradiological ${ }^{3}$ studies have shown that clinical deficits and brain shrinkage are reversible in a proportion of alcoholics following a prolonged period (months) of abstinence from alcohol. These improvements are more evident in the younger patients with shorter drinking histories. There is to date, no proven pathological explanation for this reversible brain damage. However, it can be stated categorically that neuronal loss is not reversible. Therefore we must look elsewhere for an explanation. In view of our findings of changes in the white matter in the alcoholic groups and in the knowledge that there is a constant turnover of myelin and that remyelination can occur to a limited extent in the CNS, further studies of myelin structure and metabolism should be carried out. There may well prove to be two different pathological changes in the white matter as a result of alcohol abuse: an irreversible component due to neuronal death and subsequent Wallerian degeneration, and a reversible component which may relate to subtle structural changes which can not be identified by normal subjective histological examination of human material. The basic cause of the damage has also to be elucidated as those cases with the most severe brain shrinkage usually have additional disorders such as WE and/or cirrhosis of the liver. These may well play an important part in the degenerative processes although the presence of abnormalities in the "alcoholic" group who had neither WE nor cirrhosis, suggests that the alcohol per se probably plays a significant role. Animal models of alcohol toxicity and thiamine deficiency in various combinations may prove useful in clarifying some of these issues.

\section{Conclusions}

The results of the volumetric studies of the moderate group could be said to be inconclusive because most of the changes are not significantly different from controls. However, in the context of the brain shrinkage measurements already documented in alcoholics and 
the fact that there appears to be a grading of cerebral shrinkage within the alcoholic group (those with cirrhosis or Wernicke's encephalopathy), results of moderate drinkers seem to fit between the controls and alcoholics. Since moderate drinkers are more likely to have reversible changes than severe chronic alcoholics, the differences noted in the water and lipid profiles of the white matter may be an indication of a subtle structural change which can not be identified by the usual subjective histological examination of human material. Thus there may be two different pathological changes in the white matter as a result of alcohol abuse: an irreversible component due to neuronal death and subsequent Wallerian degeneration and a reversible component as noted above.

This research was supported by a grant from the Australian Associated Brewers and the N.H. \& M.R.C. (No. 87/0564). The authors thank Ms Joy Gillies who prepared this manuscript.

\section{References}

1 Ron MA. The alcoholic brain: CT scan and psychological finding Psychol Med 1983;monograph suppl No 3:1-33.

2 Lishman WA, Jacobson RR, Acker C. Brain damage in alcoholism: current concepts Acta Med Scand 1987;222; suppl 717: $5-17$.

3 Carlen PL, Wortzman G, Holgate RC, Wilkinson DA, Rankin JG. Reversible cerebral atrophy in recently abstinent chronic alcoholics measured by computed tomographic scans. Science 1978;200:1076-8.

4 Cala LA, Jones B. Mastaglia FL, Wiley B. Brain atrophy and intellectual impairment in heavy drinkers: a clinical, psychometric and computerised tomography study. Aust NZ J Med 1978;8:147-53.

5 Walsh KW. Alcohol related brain damage: An hypothesis. Aust Alc/Drug Rev 1983;2:1-84

6 Harper CG. Neuropathology of brain damage caused by alcohol. Med J Aust 1982;2:277-82.

7 Harper CG, Kril JJ, Holloway RL. Brain shrinkage in chronic alcoholics: a pathological study. $\mathrm{Br}$ Med $J$ 1985;290:501-4

8 Harper C, Kril J. Pathological changes in alcoholic brain shrinkage. Med J Aust 1986;144:3-4.

9 Harper C, Kril J, Daly J. Are we drinking our neurones away? Br Med J 1987;294:534-6.

10 Paton A, Saunders JB. ABC of alcohol. Br Med J 1981:283: 1248-50.

11 Lelbach WK. (1974). Organic Pathology related to volume and patterns of alcohol use. In: Gibbins RJ, et al (eds). Research
Advances in Drug and Alcohol Problems. Volume I. New York. John Wiley and Sons.

12 Australian Bureau of Statistics. Alcohol and Tobacco Consumption Patterns (Catalogue No 4312.0). Canberra. Australian Bureau of Statistics, 1977.

13 Pols RG, Hawks DV. Is there a safe level of daily consumption of alcohol for men and women? National Health \& Medical Research Council Report for Health Care Committee, Canberra, 1986.

14 Hay DA, Cummins JE. Genetic dependence of alcohol related disease: animal models. Aust NZ J Med 1981;11:148-53.

15 Harper CG, Blumbergs PC. Brain weights in alcoholics. $J$ Neurol Neurosurg Psychiatry 1982;45:838-40.

16 Harper C, Kril J, Raven D, Jones N. Intracranial cavity volumes-a new method and its potential applications. Neuropathol Appl Neurobiol 1984;10:25-32.

17 Harper CG, Kril JJ, Daly JM. Brain shrinkage in alcoholics is not caused by a change in hydration: a pathological study. J Neurol Neurosurg Psychiatry 1988;51:124-7.

18 Harper CG, Kril JJ, Daly JM. The specific gravity of the brains of alcoholic and control patients: a pathological study. $\mathrm{Br} J$ Addict 1987;82:1349-54.

19 Phillips SC, Harper CG, Kril J. A quantitative histological study of the cerebellar vermis in alcoholic patients. Brain 1987;110: 301-14.

20 Harper C, Kril J. Brain atrophy in chronic alcoholic patients: a quantitative pathological study. J Neurol Neurosurg Psychiatry 1985;45:211-7.

21 Yates AJ, Thelmo W, Pappius HM. Postmortem changes in the chemistry and histology of normal and edematous brains. Am J Pathol 1975;79:555-64.

22 Shaw DM, Frizel D, Camps FE, White S. Brain electrolytes in depressive and alcoholic suicides. Br J Psychiatry 1969; 115:69-79.

23 Folch J, Lees M, Stanley GHS. A simple method for the isolation and purification of total lipids from animal tissue. $\mathrm{J} \mathrm{Biol} \mathrm{Chem}$ 1957:226:497-509.

24 Marmarou A. Poll W. Shulman K. Bhabavon H. A simple gravimetric technique for measurement of cerebral oedema. J Neurosurg 1978;49:530-7.

25 Gornall AG, Bardawill CJ, David MM. Determination of serum proteins by the Biuret reaction. J Biol Chem 1949:177:751.

26 Aherne WA, Dunnill MS. (1982) Morphometry: London. Edward Arnold.

27 O'Brien JS, Sampson EL. Lipid composition of the normal human brain: grey matter, white matter and myelin. $J$ Lipid Res 1965;6:537-44.

28 Davison AN. Wajda M. Cerebral lipids in Multiple Sclerosis. $J$ Neurochem 1962:9:427-32.

29 Cumings JN. (1965) Cerebral lipid biochemistry in the demyelinations. In: Cumings JN, Kremer MFA. (eds) "Biochemical Aspects of Neurological Disease" Philadelphia. Davis Co. 229-51.

30 Lesch P, Schmidt E, Schmidt FW. Effects of chronic alcohol abuse on the structural lipids in the human brain. $Z$ Klin Chem Klin Biochem 1972:10:410-5.

31 Chin JH. Goldstein DB. Membrane-disordering action of ethanol. Variation with membrane cholesterol content and depth of the spin label probe. Mol Pharmacol 1981:19:425-31. 